\title{
Electrochemical Reduction of Carbon Dioxide over CNT-Supported Nanoscale Copper Electrocatalysts
}

\author{
Sk. Safdar Hossain, ${ }^{1}$ Sleem ur Rahman, ${ }^{2}$ and Shakeel Ahmed ${ }^{3}$ \\ ${ }^{1}$ College of Engineering, King Faisal University, Al-Hofuf 31982, Saudi Arabia \\ ${ }^{2}$ Chemical Engineering Department, King Fahd University of Petroleum \& Minerals, Dhahran 31261, Saudi Arabia \\ ${ }^{3}$ Center for Refining and Petrochemicals, King Fahd University of Petroleum \& Minerals, Dhahran 31261, Saudi Arabia \\ Correspondence should be addressed to Sk. Safdar Hossain; snooruddin@kfu.edu.sa
}

Received 14 April 2014; Revised 15 June 2014; Accepted 15 June 2014; Published 17 July 2014

Academic Editor: Prashant Kumar

Copyright (c) 2014 Sk. Safdar Hossain et al. This is an open access article distributed under the Creative Commons Attribution License, which permits unrestricted use, distribution, and reproduction in any medium, provided the original work is properly cited.

\begin{abstract}
This paper presents the experimental investigation of copper loaded carbon nanotubes (CNTs) electrocatalysts for the electrochemical reduction of carbon dioxide. The electrocatalysts were synthesized by homogeneous deposition precipitation method (HDP) using urea as precipitating agent. The prepared catalysts were characterized by TEM, SEM, XRD, XPS, BET, and FTIR for their morphology and structure. Characterization results confirm the deposition of Cu nanoparticles (3-60 nm) on CNTs. Linear sweep voltammetry (LSV) and chronoamperometry (CA) were used to investigate the activity of the as-prepared catalysts for the electrochemical reduction of carbon dioxide. The electrocatalysts reduced $\mathrm{CO}_{2}$ with high current density in the potential range $0 \sim-3 \mathrm{~V}$ versus SCE (standard calomel electrode). Among all catalysts tested, $20 \mathrm{wt}$. \% copper loaded CNTs showed maximum activity. Gas chromatograph with TCD was used to analyze liquid phase composition. The faradaic efficiency for methanol formation was estimated to be $38.5 \%$.
\end{abstract}

\section{Introduction}

Scientific evidences are quite persuasive that the global warming has direct link with the increased level of greenhouse gases in atmosphere. Carbon dioxide $\left(\mathrm{CO}_{2}\right)$ is one of the major greenhouse gases. Its concentration stands at $390 \mathrm{ppm}$ in 2011 in comparison to $350 \mathrm{ppm}$ in 1960 [1, 2]. Substantial steps need to be taken to meet the Kyoto protocol which limits the average earth temperature rise to $2^{\circ} \mathrm{C}[2,3]$. Fossil fuel combustion for energy generation and transportation purposes is regarded as one of the main sources of $\mathrm{CO}_{2}$. Various strategies, including shifting fuel utilization pattern from fossil fuel to renewable energy, increasing the efficiency of engines, carbon dioxide sequestration, and chemical utilization, have been proposed to combat the everincreasing concentration of $\mathrm{CO}_{2}$. Of all the strategies, direct use of $\mathrm{CO}_{2}$ as feed for producing high value chemicals is particularly attractive. Electrochemical reduction of carbon dioxide (ERC) is one of the most promising methods for $\mathrm{CO}_{2}$ mitigation because (A) it uses $\mathrm{CO}_{2}$, a greenhouse gas, and water as feed, (B) it produces high economic value products like methanol, methane, ethylene, formic acid, and synthesis gas, (C) it operates at room temperature and pressure, and (D) it provides possibility of using renewable sources of energy for the process. ERC have been carried out mostly in aqueous and nonaqueous medium. ERC suffers from the requirement of high electrode overpotential and low resultant current density $[4,5]$. At high potential, if the reaction is carried out in aqueous phase, hydrogen evolution reaction competes with the ERC [6]. This seriously decreases the energy efficiency of the process. Product selectivity in electrochemical reduction of $\mathrm{CO}_{2}$ depends on many factors, such as concentration of $\mathrm{CO}_{2}$, electrode potential, temperature, electrocatalyst material, and electrolyte solution (aqueous or nonaqueous) [5]. Use of electrocatalysts has been suggested to lower the potential requirement and increase the current density [7]. Moreover, product distribution can be tuned by choosing the appropriate electrocatalyst. Since Hori's work in 1983, most of the metals in periodic table and their oxides have been tried as an electrocatalyst to achieve reasonable activity for ERC 
at low potential with high current density [8]. Copper has been found to be, till date, the most promising electrocatalyst for ECR [9]. It shows medium hydrogen overvoltage with reaction products being methanol, ethane, methane, and ethylene $[5,10]$. Copper metal $[11,12]$, fine copper particles [13], copper oxide [14-17], and modified copper oxides have been studied extensively [18].

Electrode materials have been, mostly, employed in the form of foil, plate, and rotating disc, bed of particles, or gas diffusion electrodes [19-21]. However, very limited studies have been carried out on metal supported on porous conducting materials as electrocatalysts for ERC. It has been suggested that ERC involves adsorption of the reactant species on the active material [4]; dispersing the metal on a high surface area support could well result in increased activity of the electrocatalyst. In addition, the use of an inert support enhances C-C chain growth probability, and hydrocarbon formation is favored by the presence of micropores since mass-transfer resistance is low and residence time is improved [22].

Yamamoto et al. [23] examined various metals, including copper, electrocatalyst supported on activated carbon fibers. These catalysts showed high current density and selectivity compared to the planar electrodes.

Carbon nanotubes (CNTs) have unique properties such as uniform and straight pores, nearly uniform meso- and macropore structure, inert surface properties, resistance to acid and base environments, and their electrical conductivity [24]. Their special and steady structural characteristics and morphology are quite suitable for use as support materials especially for electrochemical applications. CNTs have emerged as a popular support material for electrocatalysts for fuel cells [24]. But, to the best of our knowledge, only one study has been reported so far with CNTs as catalyst support material for ERC. Gangeri et al. used platinum and iron supported CNTs as electrocatalyst to produce long chain oxygenates due to "space restriction" effect [22]. The present work was undertaken with the objective of studying the catalytic activity of nanoscale copper electrocatalysts supported on CNTs for ERC. Copper loaded CNTs catalysts were prepared by homogenous deposition precipitation (HDP) method. The morphology, structural properties, and composition of the prepared $\mathrm{Cu} / \mathrm{CNT}$ nanocatalysts were characterized by using X-ray diffraction (XRD), $\mathrm{N}_{2}$ adsorption/desorption isotherm, energy dispersive X-ray spectroscopy (EDX), transmission electron microscopy (TEM), scanning electron microscopy (SEM), and X-ray photoelectron spectra (XPS). The effect of $\mathrm{Cu}$ loading on the catalytic activity of $\mathrm{Cu} / \mathrm{CNTs}$ for ERC was investigated in an aqueous phase divided cell.

\section{Experimental}

2.1. Catalyst Preparation. All reagents were analytical grade and were used as received without further purification.

Multiwall carbon nanotubes were used as support for the catalysts. CNTs (with purity greater than 95\% and BET surface area of $359 \mathrm{~m}^{2} / \mathrm{g}$ ) were purchased from Cheap Tubes Inc. Multiwall carbon nanotubes will be referred to as CNTs

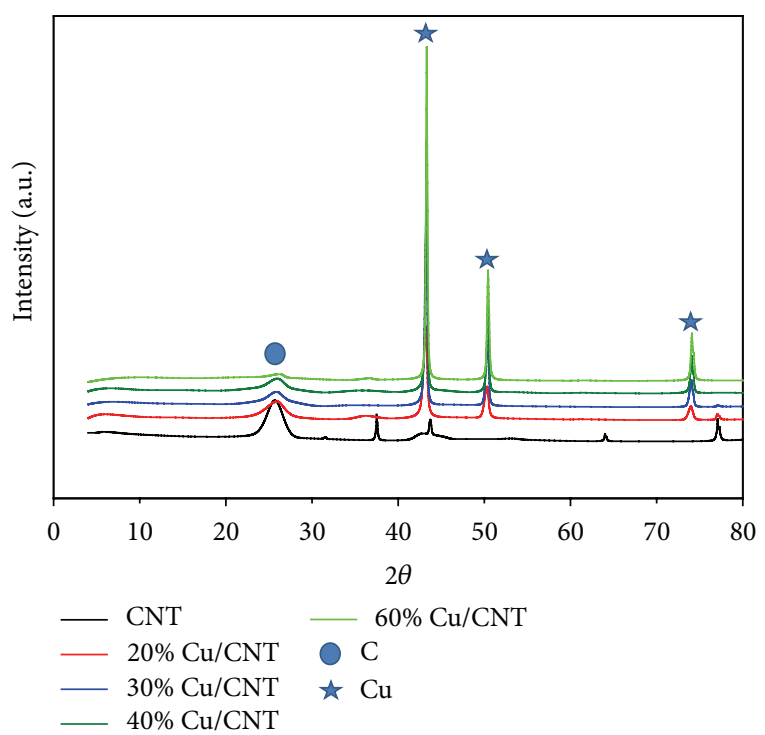

FIGURE 1: XRD pattern of $\mathrm{Cu} / \mathrm{CNT}$ catalysts with different $\mathrm{Cu}$ loading.

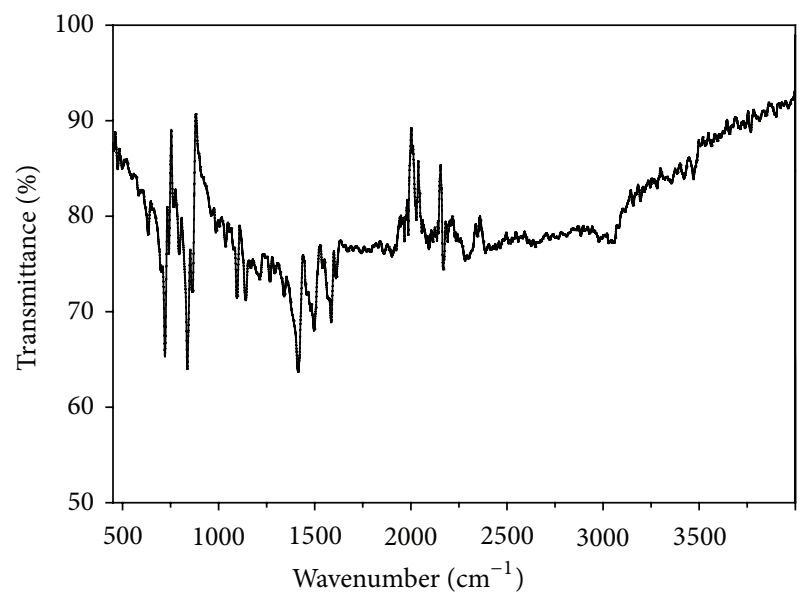

FIgURE 2: FTIR spectra of the functionalized CNT. Peaks at wavenumbers indicate types of bonding in the sample.

in this paper. The pristine CNTs have no or very little anchoring points; therefore, the CNTs were acid functionalized. The CNTs were functionalized by refluxing them with a mixture of $30 \% \mathrm{HNO}_{3}$ and $98 \% \mathrm{H}_{2} \mathrm{SO}_{4}$ at $100^{\circ} \mathrm{C}$ for $10 \mathrm{hrs}$. The suspension was filtered, washed copiously with distilled water, and dried at $120^{\circ} \mathrm{C}$ for $6 \mathrm{hrs}$ to obtain the acid functionalized CNTs powder $[25,26]$.

Copper loaded CNTs catalysts were prepared by homogeneous deposition precipitation method (HDP) using urea as precipitating agent [27]. In a typical synthesis procedure, required amount of copper nitrate pentahydrate (Merck) was added in a constantly stirred suspension made by suspending $0.8 \mathrm{~g}$ functionalized CNTs in $200 \mathrm{~mL}$ deionized water. After heating the mixture to $90^{\circ} \mathrm{C}, 30 \mathrm{~mL}$ of $0.42 \mathrm{M}$ aqueous urea solution was added dropwise. The suspension was maintained at $90^{\circ} \mathrm{C}$ with vigorous stirring for deposition to take place. 


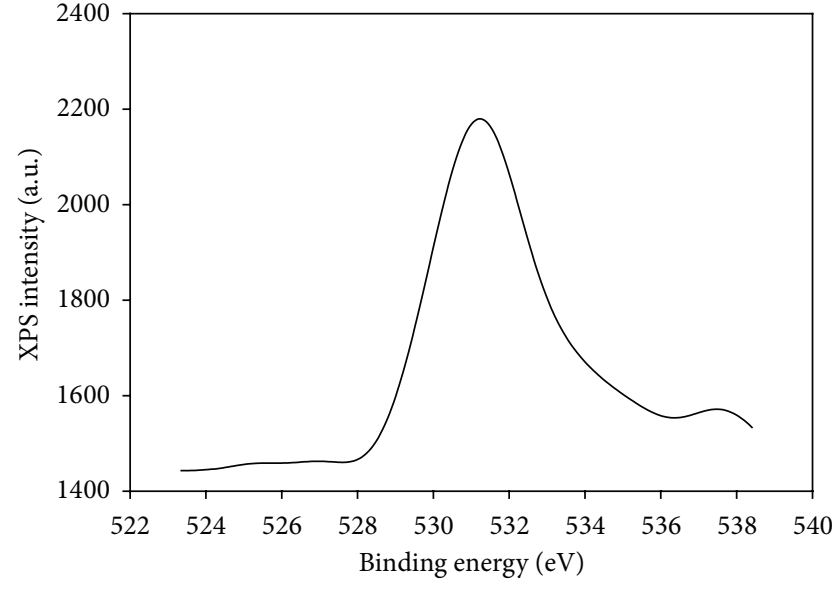

(a)

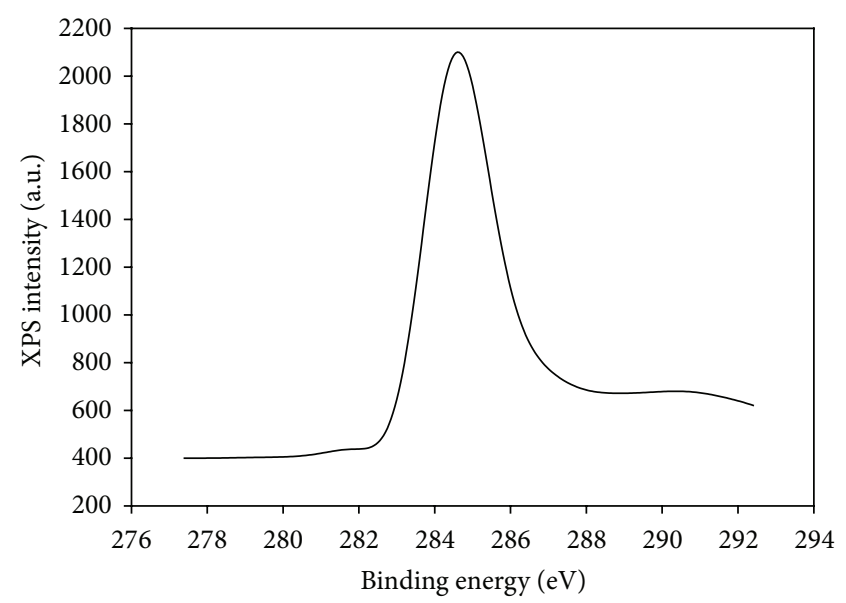

(b)

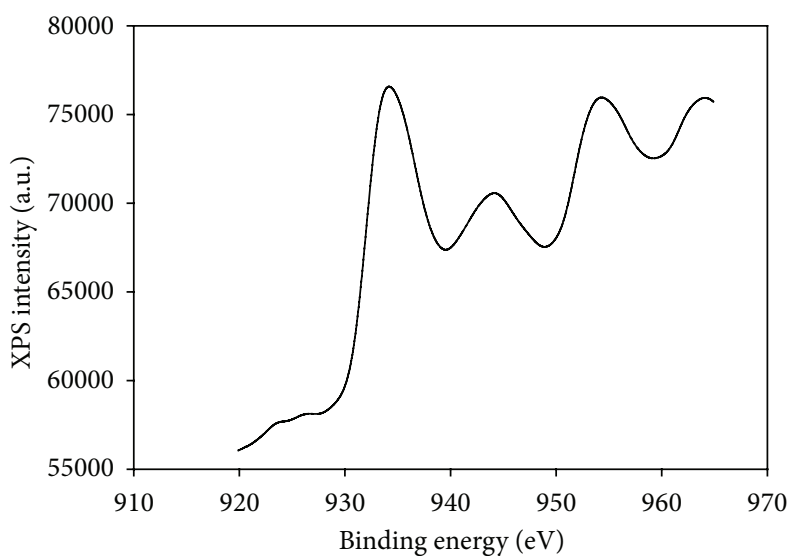

(c)

FIGURE 3: XPS spectrum of $20 \% \mathrm{Cu} / \mathrm{CNT}$ for high binding energy for relevant $\mathrm{C}_{1} \mathrm{~s}, \mathrm{Cu}_{2} \mathrm{p}_{3 / 2}$, and $\mathrm{O}_{1}$ s detailed XPS regions.

After deposition for $6 \mathrm{hrs}$, the slurry was cooled to room temperature, centrifuged, thoroughly washed with deionized water, and dried at $110^{\circ} \mathrm{C}$ for 5 hrs. The powder was calcined in a tubular furnace at $400^{\circ} \mathrm{C}$ for $3 \mathrm{hrs}$ under argon (Ar) flow of $100 \mathrm{~mL} / \mathrm{min}$. The catalyst was finally reduced to convert the catalyst into metallic form by a gas mixture $\left(10 \% \mathrm{H}_{2}\right.$ in Ar) flowing at $100 \mathrm{~mL} / \mathrm{min}$ up to $400^{\circ} \mathrm{C}$ for $3 \mathrm{hrs}$ at a heating rate of $5^{\circ} \mathrm{C} / \mathrm{min}$. By using the similar procedure with different amount of copper nitrate, different loadings of copper loaded on CNTs were prepared. The prepared catalysts were denoted as $x \%$-Cu/CNT, where $x$ represents the percent weight content of $\mathrm{Cu}$ loading by weight $(10,20,30,40,50$, and $60 \%)$.

2.2. Characterization of Catalyst. Specific surface areas (BET) and pore volume of the synthesized materials/catalysts were determined by $\mathrm{N}_{2}$ adsorption using a Micromeritics model ASAP 2000 analyzer. Prior to the measurements, the samples were degassed at $200^{\circ} \mathrm{C}$ under nitrogen flow for $5 \mathrm{hrs}$ in order to remove moisture completely. Physical adsorption of $\mathrm{N}_{2}$ was carried out in a liquid nitrogen bath maintained at $77 \mathrm{~K}$ temperature.
X-ray diffraction patterns of catalyst were collected in order to characterize the crystalline phases of the catalysts and crystal size. XRD analysis of the prepared catalyst was performed by a Rigaku diffractometer (D/MAX-IIIA, $3 \mathrm{~kW}$ ) using $\mathrm{CuK}_{\alpha}$ radiation $(40 \mathrm{kV}, 30 \mathrm{~mA}, \lambda=0.1543 \mathrm{~nm})$ to record the diffraction patterns between $20^{\circ} \geq 2 \theta \geq 80^{\circ}$ with a scan rate of $6^{\circ} \mathrm{min}^{-1}$.

Transmission electron microscopy (TEM) images were taken to determine the metal dispersion on support material along with particle size of loaded metal. An ultrahigh resolution FETEM (JEOL, JEM-2100F) at an accelerating voltage of $200 \mathrm{kV}$ was employed to capture the images of the solid samples. The morphologies of the support and catalysts were studied by using a scanning electron microscope (JEOL JSM$6460 \mathrm{LV}$ ) operated at $20 \mathrm{kV}$ equipped with energy dispersive $\mathrm{X}$-ray (EDX). EDX was carried out to find the composition of catalyst samples. Sample for both TEM and SEM was prepared by one milligram of the catalyst sonicated in $10 \mathrm{~mL}$ of ethanol for $30 \mathrm{~min}$ and then a drop of the suspension was placed on an aluminum foil which was mounted on the sample holder by means of a double sided adhesive copper tape. 


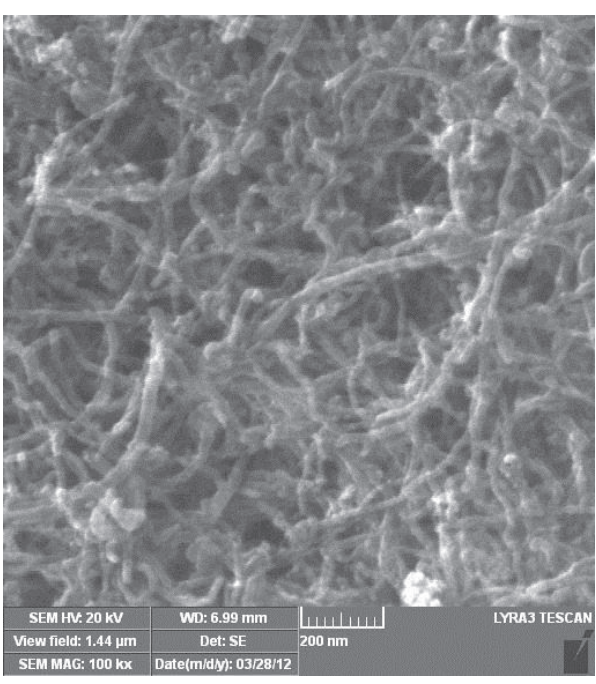

(a)

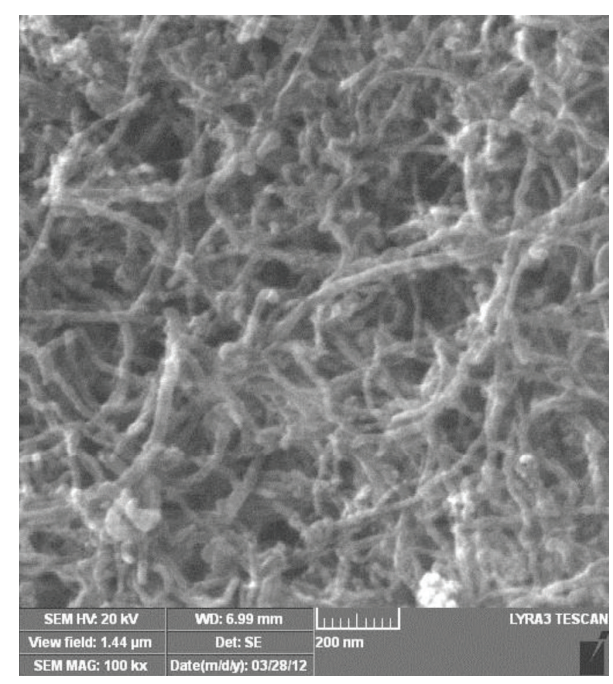

(b)

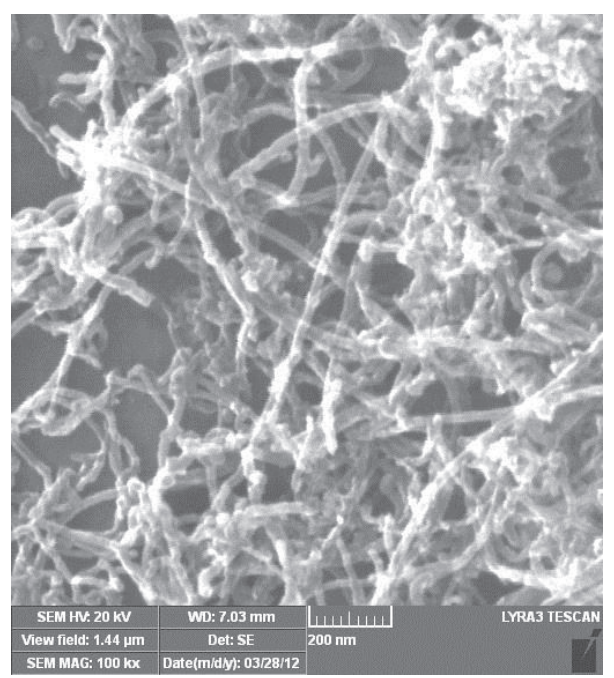

(c)

Figure 4: SEM image of (a) $10 \% \mathrm{Cu} / \mathrm{CNT}$, (b) $20 \% \mathrm{Cu} / \mathrm{CNT}$, and (c) $50 \% \mathrm{Cu} / \mathrm{CNT}$.

Fourier transform infrared (FTIR) spectra were obtained in transmittance mode on a Perkin-Elmer FC-16 FTIR spectrometer. Spectra were taken by making pellet of different powder samples with potassium bromide (KBr). Around 4$5 \mathrm{mg}$ of sample was mixed with approximately $200 \mathrm{mg}$ of $\mathrm{KBr}$ to prepare the pellets. The spectrum for each pellet was taken with the abovementioned spectrometer using 16 scans per sample at a resolution of $4 \mathrm{~cm}^{-1}$ over the range 4000$400 \mathrm{~cm}^{-1}$.

X-ray photoelectron spectra (XPS) were analyzed with a V.G. Scientific ESCALAB MKII spectrometer equipped with a dual aluminum-magnesium anode X-ray gun and a $150 \mathrm{~mm}$ concentric hemispherical analyzer. Core level photoelectron spectra were collected on a VG scientific ESCALAB MKII spectrometer equipped with a dual aluminum-magnesium anode X-ray gun and a $150 \mathrm{~mm}$ concentric hemispherical analyzer using $\mathrm{Al}-\mathrm{Ka}(\mathrm{h} v=1486.6 \mathrm{eV})$ radiation from an anode operated at $130 \mathrm{~W}$.
2.3. Electrocatalytic Activity Test. Electrochemical studies were carried out in a conventional indigenously made $\mathrm{H}$ type cell with anode and cathode compartments separated by proton conducting Nafion 117 membrane. Volume of each compartment was $250 \mathrm{~cm}^{3}$. A 0.5 molar aqueous solution of sodium bicarbonate was used both as catholyte and anolyte. Toray carbon paper coated with catalyst was used as working electrode along with platinum plate as counter electrode. Active surface area of working electrode and counter electrode was $1.0 \mathrm{~cm}^{2}$ and $8.0 \mathrm{~cm}^{2}$, respectively. Catalyst coated carbon paper was made by brush painting the catalyst ink prepared by ultrasonicating $50 \mathrm{mg}$ of the catalysts along with iso-propanol and $0.82 \mathrm{~mL}$ of $5 \%$ Nafion solution for $30 \mathrm{~min}$. Standard calomel electrode (SCE) was used as the reference electrode for the experiments. All the potentials in this study are reported with respect to SCE. Prior to the experiment, the catholyte solution was purged with high purity nitrogen for $30 \mathrm{~min}$ at $50 \mathrm{~mL} / \mathrm{min}$ to expel dissolved 
air and, subsequently, high purity (99.998\%) carbon dioxide was purged at $100 \mathrm{~mL} / \mathrm{min}$ for $1 \mathrm{hr}$ to saturate the electrolyte. The $\mathrm{pH}$ of the catholyte before and after $\mathrm{CO}_{2}$ purging was 8.67 and 7.38, respectively. The $\mathrm{pH}$ of the catholyte did not change after purging $\mathrm{CO}_{2}$ for one hour which indicates that one hour purging was sufficient to fully saturate the catholyte with $\mathrm{CO}_{2}$. Linear sweep voltammetry was carried out from 0 to $-3 \mathrm{~V}$ with scan rate of $20 \mathrm{mV} / \mathrm{s}$ and chronoamperometry was done at $-1.7 \mathrm{~V}$ for 3000 seconds. All electrochemical experiments were performed with PGSTAT 302 (MetrohmAutolab, The Netherlands). Qualitative analysis of product in the catholyte was carried out by an Agilent 7890 A gas chromatograph equipped with thermal conductivity detector (TCD). Products in the gas phase were not analyzed.

\section{Results and Discussion}

\subsection{Physical Characterization}

3.1.1. X-Ray Diffraction (XRD). The XRD analysis was carried out to investigate the diffraction structure of the $\mathrm{Cu}$ based catalysts supported on carbon nanotubes (CNTs) for different metal loading conditions. Figure 1 shows the X-ray diffraction pattern for the six catalyst samples with different loadings. As shown, the peaks located at $2 \theta=26.18^{\circ}$ and $43.18^{\circ}$ were due to the diffractions of the (002) and (100) planes of graphite-like tube wall of the CNTs [28, 29]. For all the supported catalysts, apart from the characteristic CNTs peaks characteristic diffraction peaks of zero valent $\mathrm{Cu}$ phases of (111), (200), and (220) at $2 \theta=43.23^{\circ}, 50.10^{\circ}$, and $73.97^{\circ}$, respectively, were identified (JCPDS, number 85-1326) [30]. This shows that copper was successfully deposited on CNTs by the homogenous deposition precipitation method. By comparing the peak intensities of the patterns for different $\mathrm{Cu}$ loading, the higher loading catalysts showed stronger peak intensity than the low loading catalysts. This revealed that the bigger the $\mathrm{Cu}$ particles supported on CNT, the stronger the XRD pattern. Mean Cu particle size can be determined from the characteristic $\mathrm{Cu}$ (111) peak by the Scherrer equation. The mean particle sizes of $\mathrm{Cu}$ were estimated by analyzing the line broadening of the strongest (111) diffraction peak. The mean particle sizes were calculated by the Scherrer equation, $d=0.9 \lambda / \beta \cos \theta$ where $\lambda$ is the $\mathrm{X}$-ray wavelength (1.54 $\AA$ ), $\theta$ is the Bragg angle of the peak of interest, and $\beta$ is the line broadening measured from the increased peak width at half height (FWHM) [29]. Table 1 summarizes the analysis of the XRD results. As can be seen in Table 1, with increasing $\mathrm{Cu}$ loading from $10 \%$ to $60 \%$, the crystallite size of the $\mathrm{Cu}$ particles increased significantly from 3.5 to around $60 \mathrm{~nm}$, indicating a larger sized aggregate in the case of the higher Cu loading.

3.1.2. Fourier Transform Infrared (FTIR). FTIR spectra of functionalized and $\mathrm{Cu}$ coated CNTs are shown in Figure 2. The peaks which are identified at 1360,1710 , and $3402 \mathrm{~cm}^{-1}$ characterize $\mathrm{C}-\mathrm{O}, \mathrm{C}=\mathrm{O}$, and $\mathrm{O}=\mathrm{H}$ bonds in the functionalized CNTs. Absorption peaks at $3441 \mathrm{~cm}^{-1}$ and at $1385 \mathrm{~cm}^{-1}$ correspond to the hydroxyl bands $(-\mathrm{OH})$. Peaks at 1710 and
TABLE 1: XRD data analysis results for the Cu/CNT catalysts. Crystallite size gives an idea about the size of the particles.

\begin{tabular}{lcc}
\hline Catalyst sample & FWHM & Crystallite size $(\mathrm{nm})$ \\
\hline $\mathrm{CNT}$ & 2.79 & 3.5 \\
$10 \% \mathrm{Cu} / \mathrm{CNT}$ & 2.31 & 3.38 \\
$20 \% \mathrm{Cu} / \mathrm{CNT}$ & 2.1 & 19.7 \\
$30 \% \mathrm{Cu} / \mathrm{CNT}$ & 56.6 & 0.38 \\
$40 \% \mathrm{Cu} / \mathrm{CNT}$ & 1.77 & 59.0 \\
$60 \% \mathrm{Cu} / \mathrm{CNT}$ & 1.83 & 53.9 \\
\hline
\end{tabular}

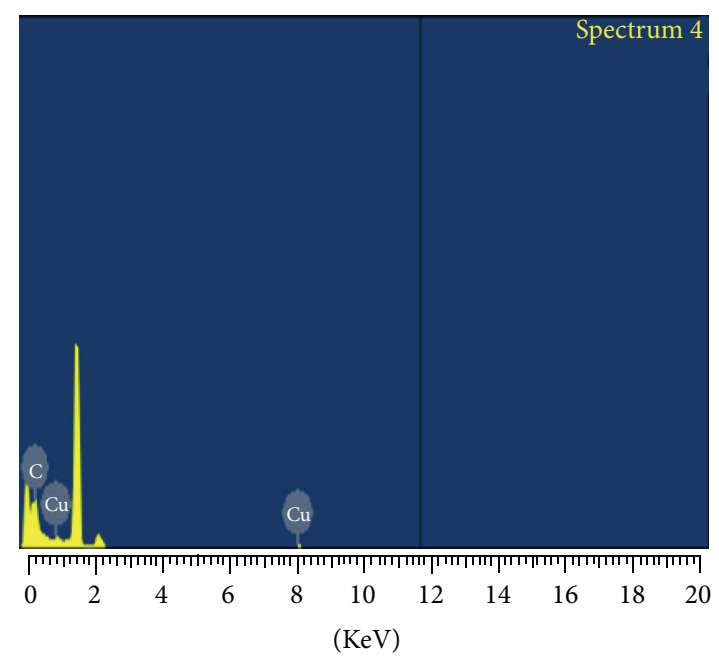

FIgURE 5: EDX spectra of $20 \% \mathrm{Cu} / \mathrm{CNT}$.

$3450 \mathrm{~cm}^{-1}$ can be attributed to acidic groups like carboxyl, phenol, and lactol. Peak at $1576 \mathrm{~cm}^{-1}$ assigns $\mathrm{C}=\mathrm{C}$ bond in CNTs. These observations show that the acid groups were successfully introduced in the CNTs [31].

3.1.3. X-Ray Spectroscopy. X-ray photoelectron was performed to acquire the detailed information about the chemical state of the $\mathrm{Cu}$ species. Figures 3(a), 3(b), and 3(c) show the XPS spectrum of $20 \mathrm{wt} . \% \mathrm{Cu} / \mathrm{CNT}$ catalyst. Spectrum in Figure 3(a) shows a strong carbon peak of $\mathrm{C} 1 \mathrm{~s}$ at $284 \mathrm{eV}$ which shows the pyrolytic carbon substrate CNT. In Figures 3(b) and 3(c) there are strong $\mathrm{Cu}$ peaks of $\mathrm{Cu}_{2} \mathrm{p}_{3}, \mathrm{Cu}_{2} \mathrm{p}_{1 / 2}$, and $\mathrm{O}_{1} \mathrm{~s}$ at about 929.46, 955, and $525.86 \mathrm{eV}$, respectively [32]. These results show that copper in metallic form has been successfully deposited on CNT.

3.1.4. SEM-EDX Analysis. Figures 4(a)-4(c) show the SEM images of $\mathrm{Cu}$ loaded CNT. It is evident from the SEM of $10 \%$ and $20 \% \mathrm{Cu} / \mathrm{CNT}$ that the $\mathrm{Cu}$ is homogenously coated on the surface of the CNT. However, as the $\mathrm{Cu}$ loading is increased, $\mathrm{Cu}$ particles tend to form agglomerates and particle size increased. Agglomeration is quite apparent in $\mathrm{Cu}$ loading $50 \%$ in Figure 4(c). This is confirmed by particle size estimated from XRD. The EDX images of $\mathrm{Cu} / \mathrm{CNT}$ (Figure 5) reveal the presence of carbon and copper. The initial unknown peak represents the aluminum holder which 


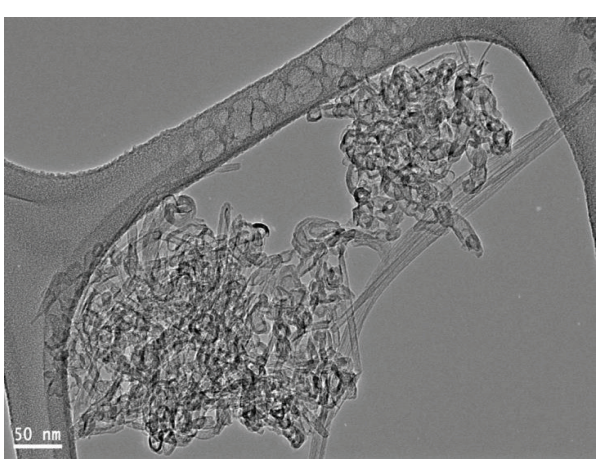

(a)

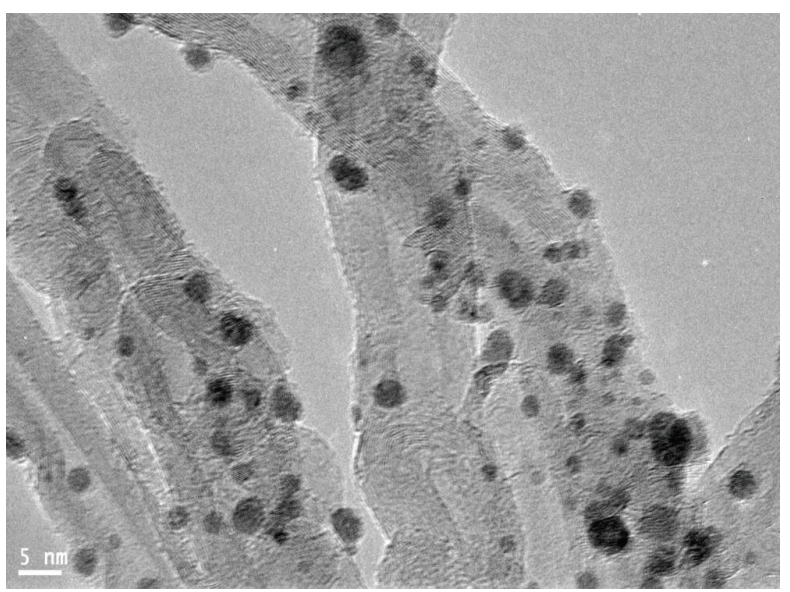

(c)

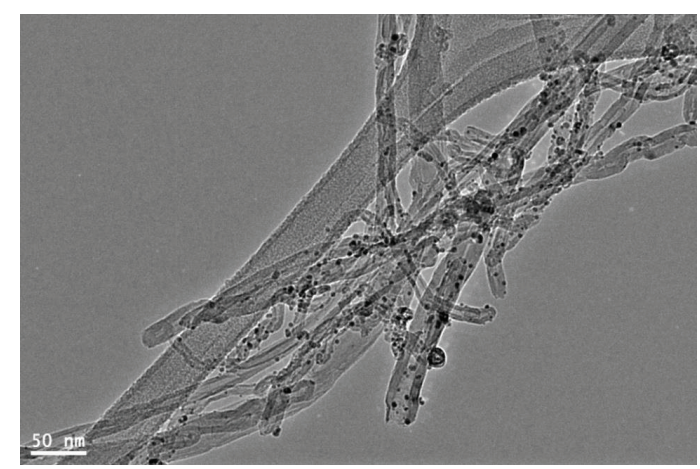

(b)

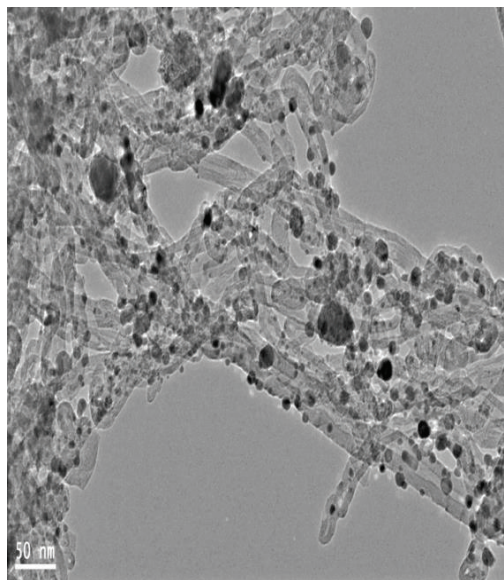

(d)

Figure 6: TEM image of (a) CNT, (b) 20 wt.\% Cu/CNT, (c) 20 wt.\% Cu/CNT at high magnification, and (d) 50 wt.\% Cu/CNT.

is used in JEOL JSM-6460LV machine. The presence of metal elements such as $\mathrm{Cu}$ reveals the successful deposition of metals on CNT.

3.1.5. TEM Analysis. TEM image of the Cu supported CNT in Figure 6 shows its characteristic tube like structure with tube diameter in the range $4-10 \mathrm{~nm}$ as specified by suppliers. It is obviously seen that $\mathrm{Cu}$ nanoparticles are homogeneously coated on the surface of CNTs and intimately attached to the CNTs. For $20 \% \mathrm{Cu}$ loading, the particle sizes are found to be of $3-5 \mathrm{~nm}$. These observations are in good agreement with the particle size estimated from X-ray diffraction data shown in Table 1. However, the TEM micrograph for $50 \mathrm{wt} . \% \mathrm{Cu}$ on CNT shows agglomeration of smaller $\mathrm{Cu}$ particles to produce larger particles $(50 \mathrm{~nm})$. At high loading of copper metals, larger copper particles are expected to display low catalytic activity.

3.1.6. $\mathrm{N}_{2}$ Adsorption Isotherms. Figure 7 shows the $\mathrm{N}_{2}$ adsorption-desorption isotherms for pure and copper loaded CNTs. All these isotherms show a typical type $1 \mathrm{~V}$ adsorption model according to the IUPAC classifications. Table 2 shows the chemical and physical properties for the CNTs-supported $\mathrm{Cu}$-catalysts including the $\mathrm{Cu}$ loading contents, BET surface area, and pore volume. The BET surface areas for the CNTssupported $\mathrm{Cu}$ catalysts range from 357 to $121.6 \mathrm{~m}^{2} / \mathrm{g}$. The
TABLE 2: Textural properties of the prepared catalysts.

\begin{tabular}{lcc}
\hline Catalyst sample & BET surface area $\mathrm{m}^{2} / \mathrm{g}$ & Pore volume $\mathrm{cm}^{3} / \mathrm{g}$ \\
\hline $\mathrm{CNT}$ & 365 & 0.56 \\
$10 \% \mathrm{Cu} / \mathrm{CNT}$ & 347 & 0.41 \\
$20 \% \mathrm{Cu} / \mathrm{CNT}$ & 339 & 0.40 \\
$30 \% \mathrm{Cu} / \mathrm{CNT}$ & 257 & 0.31 \\
$40 \% \mathrm{Cu} / \mathrm{CNT}$ & 180 & 0.26 \\
$60 \% \mathrm{Cu} / \mathrm{CNT}$ & 121 & 0.20 \\
\hline
\end{tabular}

averaged crystallite size of Cu supported on CNTs (estimated on the basis of TEM image) ranges from 3.8 to $59 \mathrm{~nm}$, which depends on the $\mathrm{Cu}$ loading content. As increasing the $\mathrm{Cu}$ content of the CNTs supported Cu catalysts, both BET surface areas and the pore volume decreased, accompanied with the increase of the size of the $\mathrm{Cu}$ particles. Generally, the decrease of the $\mathrm{Cu}$ dispersion or the increase of the particle size will lead to the decrease of the catalyst activity. From the above characterization results, it is concluded that morphologies and structure of the CNT-supported catalysts depend on the extent of $\mathrm{Cu}$ loading. This variation in properties is expected to have a significant impact on the electrocatalytic activity of the prepared catalysts. 


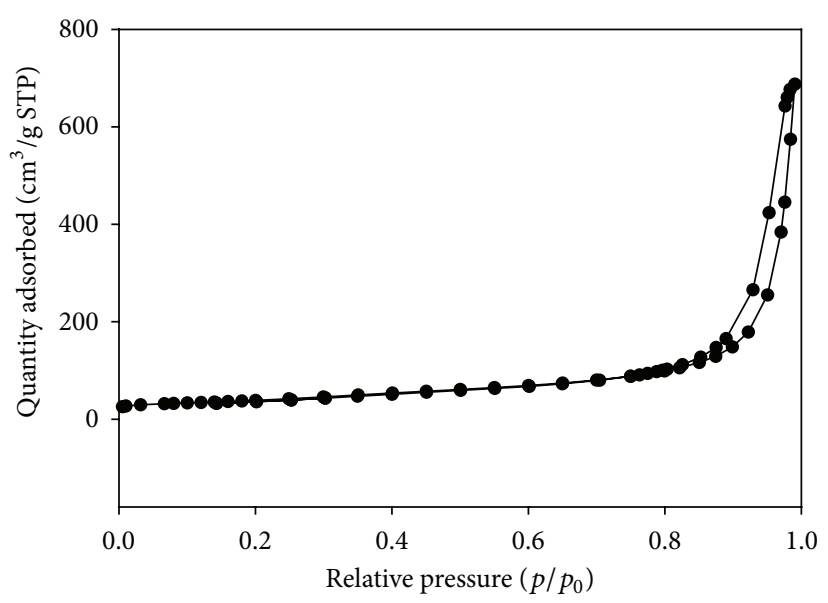

(a)

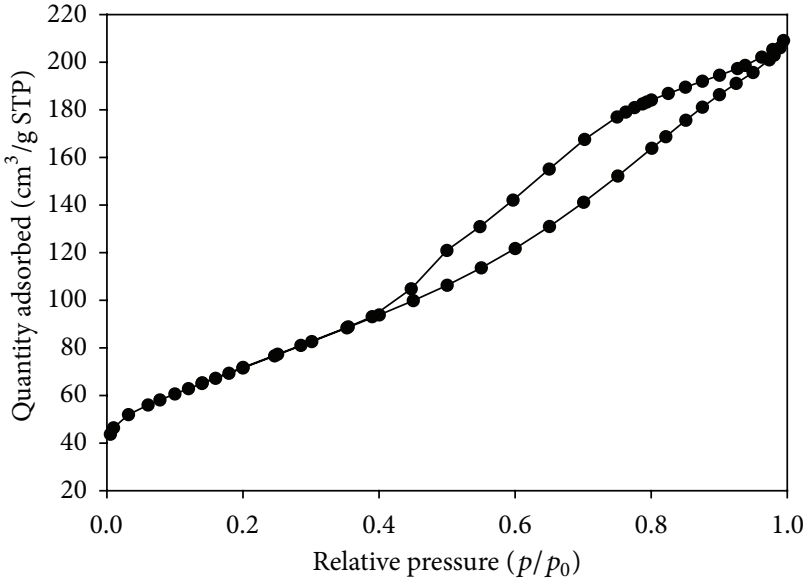

(b)

FIGURE 7: $\mathrm{N}_{2}$ adsorption-desorption isotherms of (a) CNT and (b) $20 \% \mathrm{Cu} / \mathrm{CNT}$. Hysteresis in the adsorption-desorption indicates presence of micropores.

\subsection{Electrochemical Testing}

3.2.1. Linear Sweep Voltammetry. In this study initially $10 \%$ nominal $\mathrm{Cu}$ content was selected to prepare catalyst for ERC. Figure 8 shows the linear sweep voltammetry (LSV) curves in the 0 to $-3.0 \mathrm{~V}$ range for $10 \% \mathrm{Cu} / \mathrm{CNT}$ deposited on carbon paper under different conditions. After the onset potential (i.e., the potential at which current shows its first nonzero value), there exists a linear relationship in the current and potential for the rest of the scan range with absence of any evident cathodic reduction peak. For both cases, there was no detectable physical change in the electrode. This shows that the carbon paper and catalysts were physically stable in working potential. In absence of $\mathrm{CO}_{2}$, entire current is due to production of $\mathrm{H}_{2}$ by HER. But in $\mathrm{CO}_{2}$ saturated electrolyte, two competing reactions occur: $\mathrm{CO}_{2}$ reduction and $\mathrm{H}_{2}$ evolution reaction. HER is an undesirable side reaction of ERC as it consumes electrical energy that was meant for ERC. Under the $\mathrm{N}_{2}$ saturation, the current density is found to be $0.0045 \mathrm{~A} / \mathrm{cm}^{2}$ whereas, under $\mathrm{CO}_{2}$ saturation, it shows current density of $0.008 \mathrm{~A} / \mathrm{cm}^{2}$ at $-1.5 \mathrm{~V}$. Difference in current density for the two cases arises from the contribution from the $\mathrm{CO}_{2}$ reduction which takes place under $\mathrm{CO}_{2}$ saturation. The observed higher current with $\mathrm{CO}_{2}$ saturated solution is in line with some of the findings of previous studies $[18,33-$ 35]. However, there are studies reporting that the current density under $\mathrm{CO}_{2}$ saturated condition was lower in the $\mathrm{N}_{2}$ saturated solution $[16,36,37]$. In our case the increased current density under $\mathrm{CO}_{2}$ saturated condition shows that the CNT-supported $\mathrm{Cu}$ catalysts are catalytically active for the ERC. Cathodic current obtained in our studies is higher than the results reported in the available literature [11, 14, 18, 37]. This increase in current could be due to the excellent activity of the highly dispersed copper particles on high surface area CNT $\left(400 \mathrm{~m}^{2} / \mathrm{g}\right)$. Similar results were obtained by Yamamoto et al. on porous activated carbon [23].

In order to study the effect of $\mathrm{Cu}$ content on the ERC and the optimum loading, we prepare catalysts with different

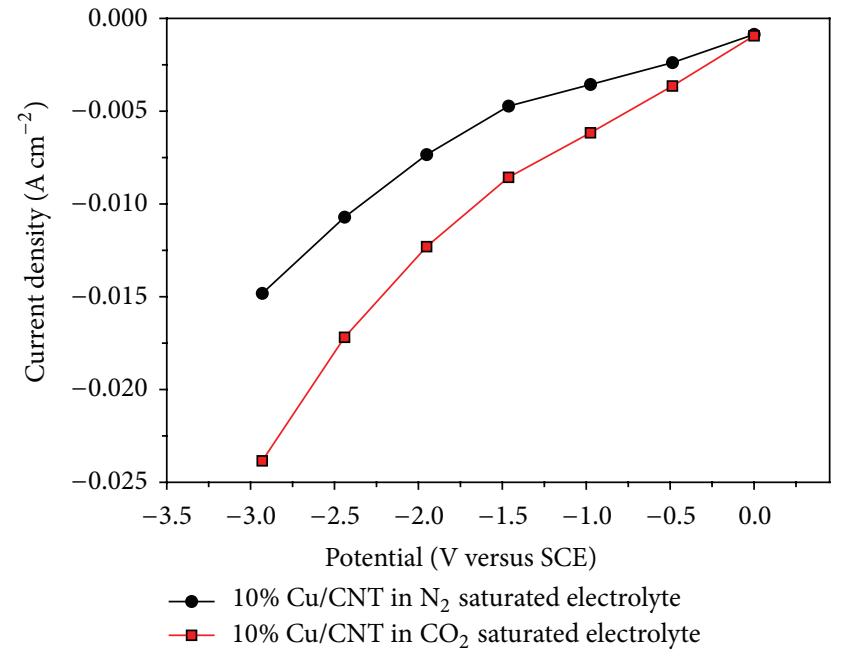

FIGURE 8: Linear sweep voltammetry of $10 \% \mathrm{Cu} / \mathrm{CNT}$ in $\mathrm{N}_{2}$ and $\mathrm{CO}_{2}$ saturated solution in $0.5 \mathrm{M} \mathrm{NaHCO}_{3}$. The potential range was $0 \sim$ $-3 \mathrm{~V}$ versus SCE with $20 \mathrm{mV} / \mathrm{s}$.

metal loading on CNTs from 10 to $60 \%$ which were prepared and tested. Figure 9 shows the effect of copper loading on the current-potential curve. In theory, the catalytic activity increases with the metal content in the catalyst. More active sites provide better probability of reactants reacting. Therefore, cathodic current was found to increase with increase in copper loading till $20 \%$, and with further increase in loading, as shown in Figure 9. However, with further increase in metal loading, current eventually started decreasing. For example, currents for $10 \% \mathrm{Cu} / \mathrm{CNT}$ and $20 \% \mathrm{Cu} / \mathrm{CNT}$ at $-1.5 \mathrm{~V}$ were $0.004 \mathrm{~A} / \mathrm{cm}^{2}$ and $0.0175 \mathrm{~A} / \mathrm{cm}^{2}$, respectively. At the same potential, 30\% $\mathrm{Cu} / \mathrm{CNT}$ showed $0.012 \mathrm{~A} / \mathrm{cm}^{2}$ current and further increase in loading has no impact on the current. Similar observation was made by Lee et al. in ERC copper loaded gas diffusion electrode [38]. This can be explained by 


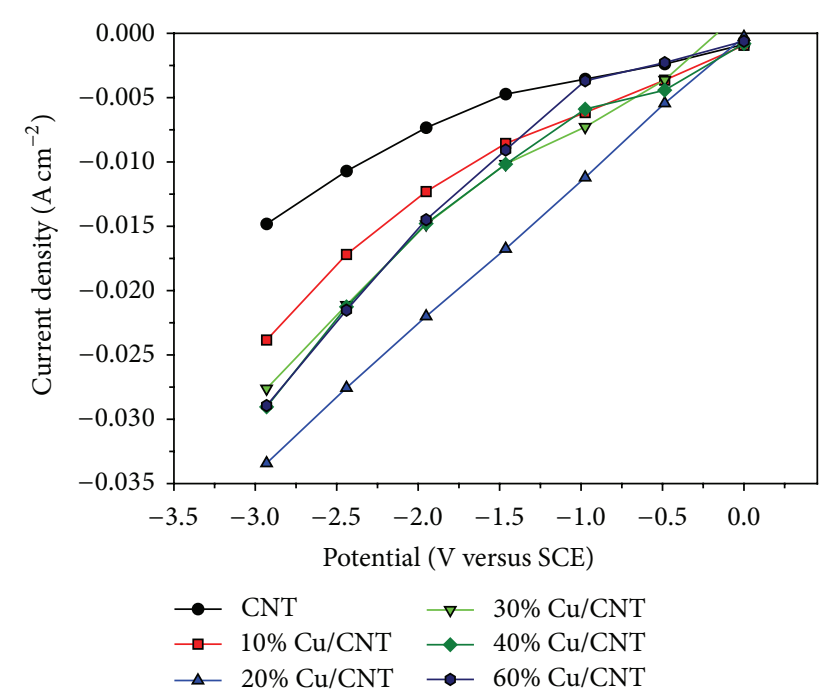

FIGURE 9: Linear sweep voltammetry of $\mathrm{Cu} / \mathrm{CNT}$ in $\mathrm{CO}_{2}$ saturated solution in $0.5 \mathrm{M} \mathrm{NaHCO}_{3}$. The potential range was $0 \sim-3 \mathrm{~V}$ versus SCE with $20 \mathrm{mV} / \mathrm{s}$.

the TEM and XRD of the catalyst. Beyond 20\% Cu loading the size of the particles increased coupled with active sites becoming increasingly inaccessible for the reactant due to the reduced surface area and micropore sizes because of pore blocking and agglomeration of the copper particles. Therefore, the optimum loading for the CNT catalyst prepared by homogeneous deposition and precipitation is $20 \%$.

3.2.2. Chronoamperometry. To study the long term performance of the catalyst, potentiostatic electrolysis was carried out at $-1.7 \mathrm{~V}$ for $6000 \mathrm{~s}$. Results are shown in Figure 10. The current of the ERC increases with increase in copper loading until it reaches $20 \%$ and then decreases with further increase in copper content. This is consistent with the results from the LSV. The result shows that copper supported on CNT is catalytically active for at least $6000 \mathrm{~s}$.

Methanol concentration in the catholyte was measured by GC equipped with TCD. Prior to the GC analysis, methanol was extracted from the bicarbonate solution in ether. Faradaic efficiency (FE) for methanol production was measured by the following formula:

$$
\mathrm{FE}=\frac{n F m}{I t},
$$

where $n$ is number of electrons involved in the reaction to produce the product and it is six for methanol generation, $F$ is the Faraday's constant, $m$ is moles of product formed, $I$ is the total current in ampere, and $t$ is the time in seconds. Figure 11 shows the Faradaic efficiency of methanol production as a function of potential. The highest $\mathrm{FE}$ for methanol formation from $\mathrm{CO}_{2}$ was found to be $38.4 \%$ and it was achieved at $-1.7 \mathrm{~V}$. The products formed in the gas phase were not detected.

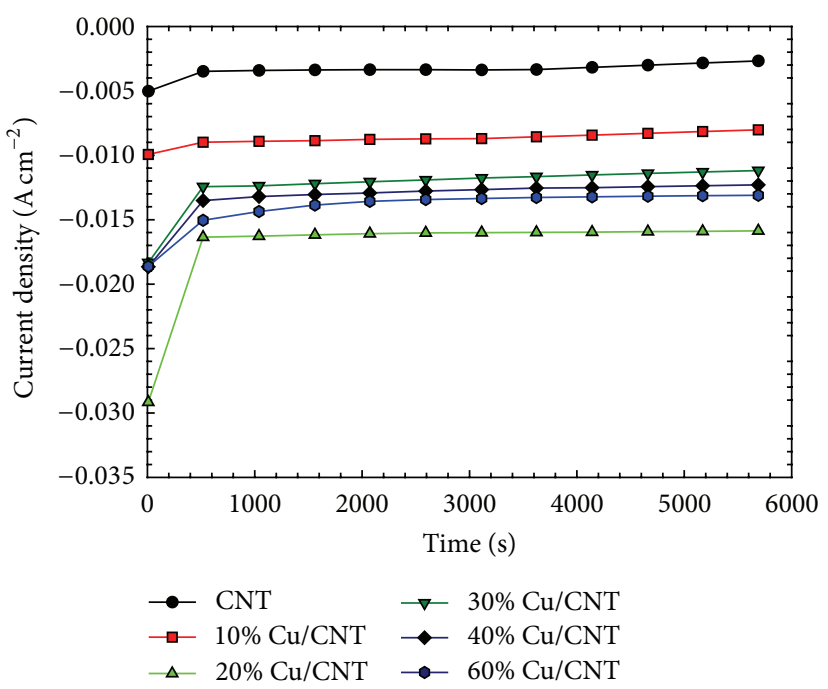

FIGURE 10: The current responses for the supported catalyst under various loading under a constant potential of $-1.7 \mathrm{~V}$ in $\mathrm{CO}_{2}$ saturated $0.5 \mathrm{M} \mathrm{NaHCO}_{3}$ solution.

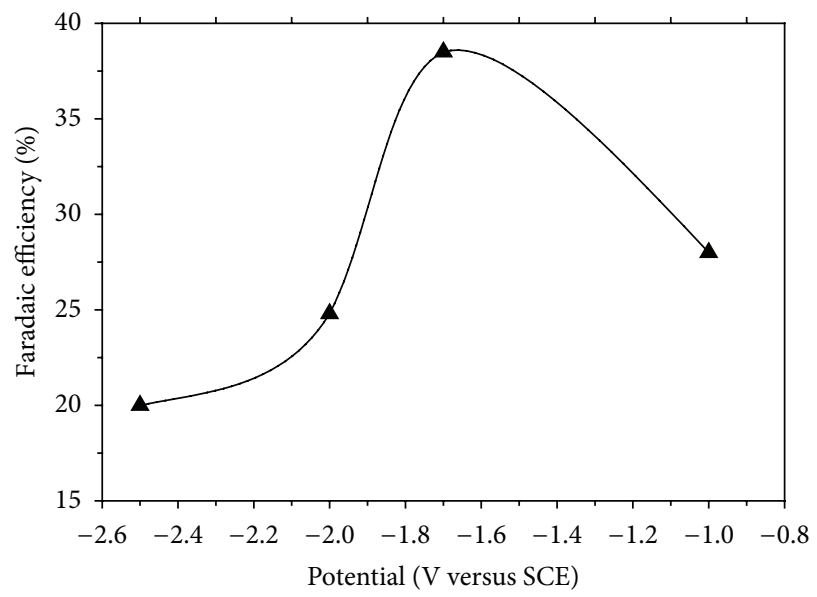

FIGURE 11: Faradaic efficiency for methanol formation after $100 \mathrm{~min}$.

\section{Conclusions}

Copper-supported carbon nanotube catalysts were prepared by deposition-precipitation method. Linear sweep voltammetry and chronoamperometry results show that all the prepared catalysts showed electrocatalytic activity towards the electrochemical reduction of carbon dioxide to methanol. The characterization results further showed that all electrocatalysts are stable and catalytically active in the potential window of the electrochemical reduction. The degree of copper metal loading on the CNT had an impact on the performance of the synthesized catalysts. The catalyst with $20 \mathrm{wt}$. \% loading of copper was found to be the best performing catalyst among all the catalysts prepared and tested. It showed the highest current density in chronoamperometry and LSV with low onset potential. Therefore, it is concluded that $20 \mathrm{wt} . \%$ copper metal loading is the optimum metal loading on CNT for the electrochemical reduction of carbon 
dioxide. This metal loading provides compromise between the amount of metal active sites for the reaction to take place and the increase in metal particle size due to agglomeration which greatly reduces the activity of the catalyst. Methanol was detected as the primary reduction product by gas chromatography.

\section{Conflict of Interests}

The authors declare that there is no conflict of interests regarding the publication of this paper.

\section{Acknowledgment}

The support by King Fahd University of Petroleum and Minerals (KFUPM) through Project 08-ENE54-4 is gratefully acknowledged.

\section{References}

[1] M. Ball and M. Wietschel, "The future of hydrogen-opportunities and challenges," International Journal of Hydrogen Energy, vol. 34, no. 2, pp. 615-627, 2009.

[2] G. Centi and S. Perathoner, "Opportunities and prospects in the chemical recycling of carbon dioxide to fuels," Catalysis Today, vol. 148, no. 3-4, pp. 191-205, 2009.

[3] I. Omae, Coordination Chemistry Reviews, 2012.

[4] G. Centi, S. Perathoner, G. Winè, and M. Gangeri, "Electrocatalytic conversion of $\mathrm{CO}_{2}$ to long carbon-chain hydrocarbons," Green Chemistry, vol. 9, no. 6, pp. 671-678, 2007.

[5] M. Gattrell, N. Gupta, and A. Co, "A review of the aqueous electrochemical reduction of $\mathrm{CO}_{2}$ to hydrocarbons at copper," Journal of Electroanalytical Chemistry, vol. 594, no. 1, pp. 1-19, 2006.

[6] D. T. Whipple and P. J. A. Kenis, "Prospects of CO2 utilization via direct heterogeneous electrochemical reduction," Journal of Physical Chemistry Letters, vol. 1, no. 24, pp. 3451-3458, 2010.

[7] M. A. Scibioh and B. Vishwanathan, "Electrochemical reduction of carbon dioxide: a status report," Proceedings of Indian National Science Academy A, vol. 70, pp. 407-462, 2004.

[8] M. Jitaru, "Electrochemical carbon dioxide reductionfundamental and applied topics," Journal of the University of Chemical Technology and Metallurgy, vol. 42, pp. 333-344, 2007.

[9] Y. Hori, C. G. Vayenas, R. E. White, and M. E. GamboaAldeco, "Electrochemical $\mathrm{CO}_{2}$ reduction on metal electrodes," in Modern Aspects of Electrochemistry, Springer, New York, NY, USA, 2008.

[10] S. Kaneco, K. Iiba, H. Katsumata, T. Suzuki, and K. Ohta, "Effect of sodium cation on the electrochemical reduction of $\mathrm{CO}_{2}$ at a copper electrode in methanol," Journal of Solid State Electrochemistry, vol. 11, no. 4, pp. 490-495, 2007.

[11] Y. Hori, A. Murata, and R. Takahashi, "Formation of hydrocarbons in the electrochemical reduction of carbon dioxide at a copper electrode in aqueous solution," Journal of the Chemical Society, Faraday Transactions: Physical Chemistry in Condensed Phases, vol. 85, no. 8, pp. 2309-2326, 1989.

[12] S. Kaneco, K. Iiba, N. Hiei, K. Ohta, T. Mizuno, and T. Suzuki, "Electrochemical reduction of carbon dioxide to ethylene with high Faradaic efficiency at a $\mathrm{Cu}$ electrode in $\mathrm{CsOH} /$ methanol," Electrochimica Acta, vol. 44, no. 26, pp. 4701-4706, 1999.
[13] S. Kaneco, Y. Ueno, H. Katsumata, T. Suzuki, and K. Ohta, "Electrochemical reduction of $\mathrm{CO}_{2}$ in copper particle-suspended methanol," Chemical Engineering Journal, vol. 119, no. 2-3, pp. 107-112, 2006.

[14] K. W. Frese Jr., "Electrochemical reduction of $\mathrm{CO}_{2}$ at intentionally oxidized copper electrodes," Journal of the Electrochemical Society, vol. 138, no. 11, pp. 3338-3344, 1991.

[15] S. Ohya, S. Kaneco, H. Katsumata, T. Suzuki, and K. Ohta, "Electrochemical reduction of $\mathrm{CO}_{2}$ in methanol with aid of $\mathrm{CuO}$ and $\mathrm{Cu}_{2} \mathrm{O}$," Catalysis Today, vol. 148, no. 3-4, pp. 329-334, 2009.

[16] T. Y. Chang, R. M. Liang, P. W. Wu, J. Y. Chen, and Y. C. Hsieh, "Electrochemical reduction of $\mathrm{CO}_{2}$ by $\mathrm{Cu}_{2} \mathrm{O}$-catalyzed carbon clothes," Materials Letters, vol. 63, no. 12, pp. 1001-1003, 2009.

[17] M. Le, M. Ren, Z. Zhang, P. T. Sprunger, R. L. Kurtz, and J. C. Flake, "Electrochemical reduction of $\mathrm{CO}_{2}$ to $\mathrm{CH}_{3} \mathrm{OH}$ at copper oxide surfaces," Journal of the Electrochemical Society, vol. 158, no. 5, pp. E45-E49, 2011.

[18] A. Bandi, "Electrochemical reduction of carbon dioxide on conductive metallic oxides," Journal of the Electrochemical Society, vol. 137, no. 7, pp. 2157-2160, 1990.

[19] C. Delacourt, L. P. Ridgway, B. K. John, and J. Newman, "Design of an electrochemical cell making syngas $\left(\mathrm{CO}+\mathrm{H}_{2}\right)$ from $\mathrm{CO}_{2}$ and $\mathrm{H}_{2} \mathrm{O}$ reduction at room temperature," Journal of the Electrochemical Society, vol. 155, pp. B42-B49, 2008.

[20] C. Oloman and H. Li, "Electrochemical processing of carbon dioxide," ChemSusChem, vol. 1, no. 5, pp. 385-391, 2008.

[21] D. T. Whipple, E. C. Finke, and P. J. A. Kenis, "Microfluidic reactor for the electrochemical reduction of carbon dioxide: the effect of pH," Electrochemical and Solid-State Letters, vol. 13, no. 9, pp. B109-B111, 2010.

[22] M. Gangeri, S. Perathoner, S. Caudo et al., "Fe and Pt carbon nanotubes for the electrocatalytic conversion of carbon dioxide to oxygenates," Catalysis Today, vol. 143, no. 1-2, pp. 57-63, 2009.

[23] T. Yamamoto, D. A. Tryk, A. Fujishimal, and H. Ohata, "Production of syngas plus oxygen from $\mathrm{CO}_{2}$ in a gas-diffusion electrode-based electrolytic cell," Electrochimica Acta, vol. 47, no. 20, pp. 3327-3334, 2002.

[24] P. Serp, M. Corrias, and P. Kalck, "Carbon nanotubes and nanofibers in catalysis," Applied Catalysis A: General, vol. 253, no. 2, pp. 337-358, 2003.

[25] P. Kumar, J.-S. Park, P. Randhawa, S. Sharma, M.-S. Shin, and S. S. Sekhon, "A study on the effect of different chemical routes on functionalization of MWCNTs by various groups (-COOH, $\mathrm{SO}_{3} \mathrm{H},-\mathrm{PO}_{3} \mathrm{H}_{2}$ )," Nanoscale Research Letters, vol. 6, no. 1, p. 583, 2011.

[26] M. S. Saha and A. Kundu, "Functionalizing carbon nanotubes for proton exchange membrane fuel cells electrode," Journal of Power Sources, vol. 195, no. 19, pp. 6255-6261, 2010.

[27] M. L. Toebes, M. K. van der Lee, L. M. Tang et al., "Preparation of carbon nanofiber supported platinum and ruthenium catalysts: comparison of ion adsorption and homogeneous deposition precipitation," The Journal of Physical Chemistry B, vol. 108, no. 31, pp. 11611-11619, 2004.

[28] Z. T. Liu, C. X. Wang, Z. W. Liu, and J. Lu, "Selective hydrogenation of cinnamaldehyde over Pt-supported multi-walled carbon nanotubes: Insights into the tube-size effects," Applied Catalysis A: General, vol. 344, no. 1-2, pp. 114-123, 2008.

[29] T. Hou, L. Yuan, T. Ye et al., "Hydrogen production by lowtemperature reforming of organic compounds in bio-oil over a CNT-promoting Ni catalyst," International Journal of Hydrogen Energy, vol. 34, no. 22, pp. 9095-9107, 2009. 
[30] X. Wang, F. Zhang, B. Xia et al., "Controlled modification of multi-walled carbon nanotubes with $\mathrm{CuO}, \mathrm{Cu}_{2} \mathrm{O}$ and $\mathrm{Cu}$ nanoparticles," Solid State Sciences, vol. 11, no. 3, pp. 655-659, 2009.

[31] C. Branca, F. Frusteri, V. Magazù, and A. Mangione, "Characterization of carbon nanotubes by TEM and infrared spectroscopy," The Journal of Physical Chemistry B, vol. 108, no. 11, pp. 3469-3473, 2004.

[32] M. C. Biesinger, L. W. M. Lau, A. R. Gerson, and R. S. C. Smart, "Resolving surface chemical states in XPS analysis of first row transition metals, oxides and hydroxides: $\mathrm{Sc}, \mathrm{Ti}, \mathrm{V}, \mathrm{Cu}$ and $\mathrm{Zn}$," Applied Surface Science, vol. 257, no. 3, pp. 887-898, 2010.

[33] N. Spataru, K. Tokuhiro, C. Terashima, T. N. Rao, and A. Fujishima, "Electrochemical reduction of carbon dioxide at ruthenium dioxide deposited on boron-doped diamond," Journal of Applied Electrochemistry, vol. 33, no. 12, pp. 1205-1210, 2003.

[34] S. Kaneco, K. Iiba, N.-H. Hiei, K. Ohta, T. Mizuno, and T. Suzuki, "Electrochemical reduction of carbon dioxide to hydrocarbons with high faradaic efficiency in $\mathrm{LiOH} /$ methanol," Journal of Physical Chemsitry, vol. 103, pp. 7456-7460, 1999.

[35] K. Hara, A. Kudo, and T. Sakata, "Electrochemical $\mathrm{CO}_{2}$ reduction on a glassy carbon electrode under high pressure," Journal of Electroanalytical Chemistry, vol. 421, no. 1-2, pp. 1-4, 1997.

[36] N. Furuya, T. Yamazaki, and M. Shibata, "High performance $\mathrm{Ru}-\mathrm{Pd}$ catalysts for $\mathrm{CO}_{2}$ reduction at gas-diffusion electrodes," Journal of Electroanalytical Chemistry, vol. 431, no. 1, pp. 39-41, 1997.

[37] M. C. M. R. Gonçalves, J. A. D. Condeço, T. C. D. Pardal, D. M. Roncero, D. M. F. Santos, and C. A. C. Sequeirac, "Electrochemical reduction of carbon dioxide for fuel cell utilisation," ECS Transactions, vol. 3, pp. 49-56, 2007.

[38] K. R. Lee, J. H. Lim, J. K. Lee, and H. S. Chun, "Reduction of carbon dioxide in 3-dimensional gas diffusion electrodes," Korean Journal of Chemical Engineering, vol. 16, no. 6, pp. 829836, 1999. 

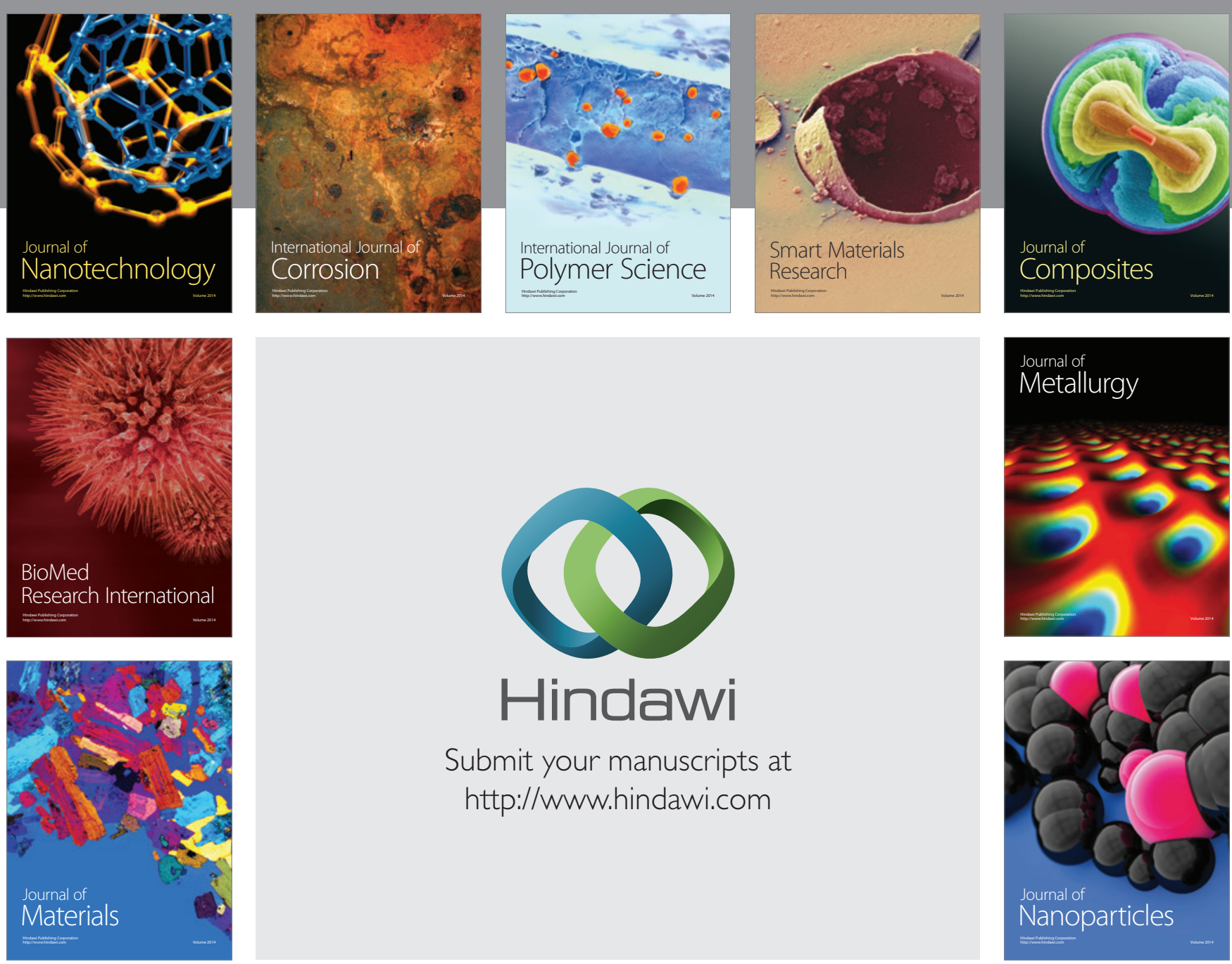

Submit your manuscripts at http://www.hindawi.com
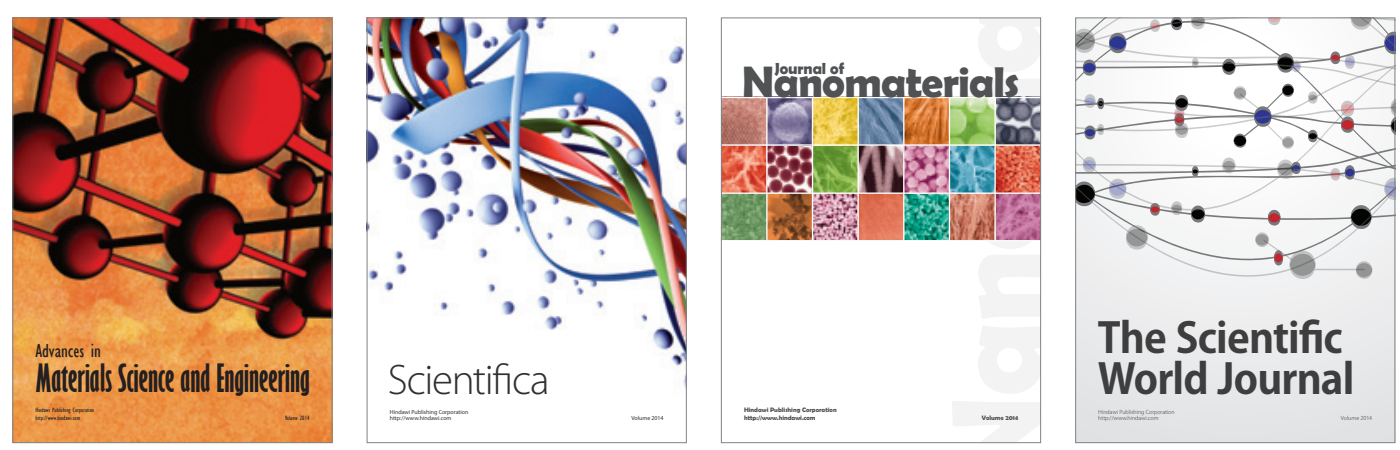

\section{The Scientific World Journal}
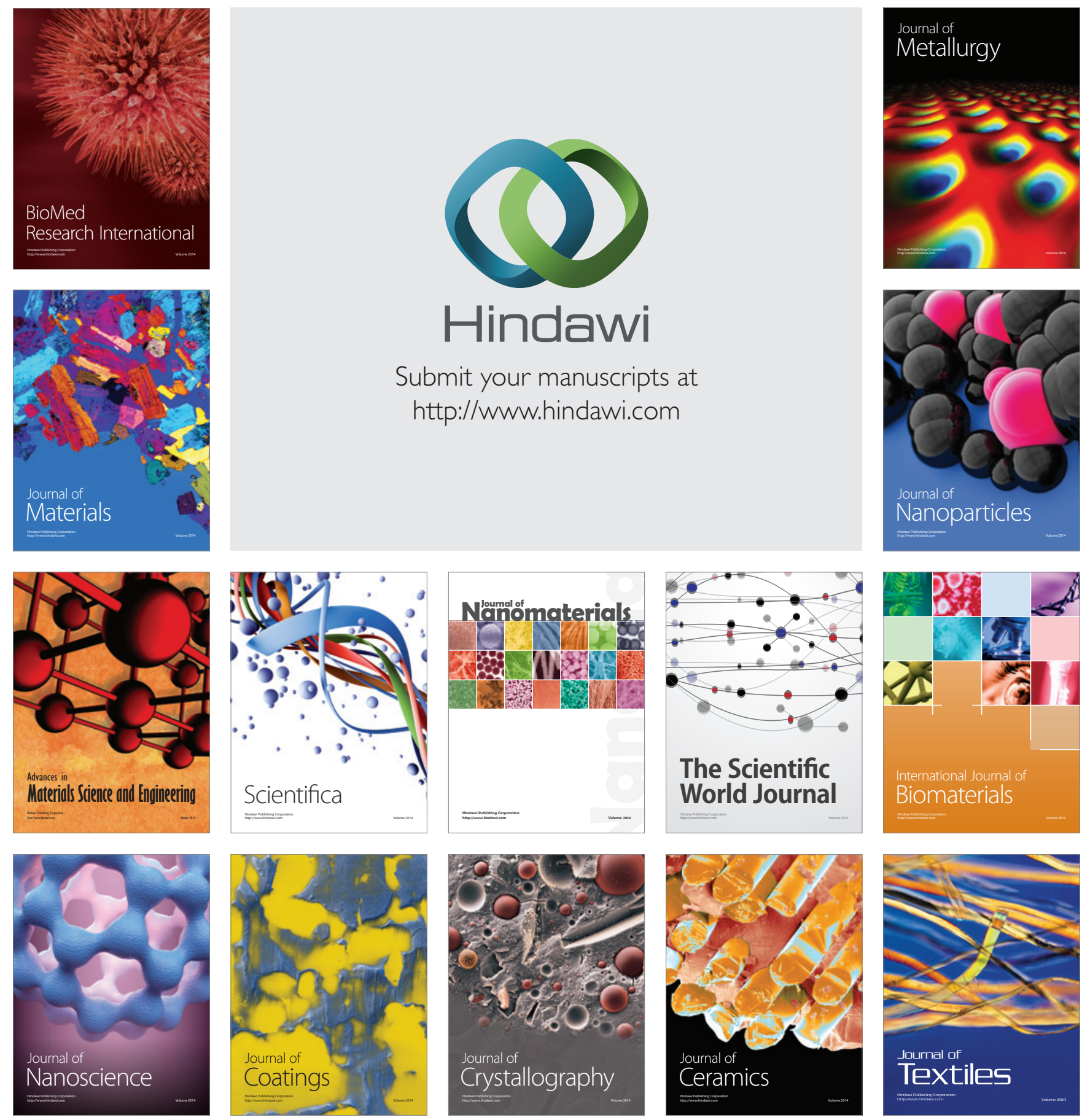